\title{
Primary spinal epidural diffuse large B-cell lymphoma with paraplegia as the first manifestation: a case report
}

\author{
Yefei Shu' \\ Anlong Wang ${ }^{2}$ \\ $\mathrm{Li} \mathrm{Yi}{ }^{3}$ \\ Xiaofeng $X u^{\prime}$ \\ Wei Yang'
}

\begin{abstract}
'Department of Oncology and Hematology, Zhejiang Provincial Integrated Chinese and Western Medicine Hospital (Hangzhou Red Cross Hospital), Hangzhou, People's Republic of China; ${ }^{2}$ Department of Radiology, Zhejiang Provincial Integrated Chinese and Western Medicine Hospital (Hangzhou Red Cross Hospital), Hangzhou, People's Republic of China; ${ }^{3}$ Departments of Pathology, Zhejiang Provincial Integrated Chinese and Western Medicine Hospital (Hangzhou Red Cross Hospital), Hangzhou, People's Republic of China
\end{abstract}

This article was published in the following Dove Press journal: OncoTargets and Therapy

\begin{abstract}
Primary spinal epidural diffuse large B-cell lymphoma (DLBCL) is rare and often easily misdiagnose. Here, we presented a case of primary spinal epidural DLBCL with paraplegia as the first manifestation. He was misdiagnosed as thoracic disc herniation and thoracic tuberculosis successively. DLBCL was confirmed after surgery ultimately. After 6 cycles of chemotherapy with R-CHOPE, the patient went back to normal life without relapse during 2-year follow-up. Primary spinal epidural lymphoma should be suspected in patients with spinal cord compression with imaging showing isointense, homogeneous extradural contiguous level compressive soft-tissue lesion without bony involvement and previous history of cancer.
\end{abstract}

Keywords: epidural, diffuse large B-cell lymphoma

\section{Introduction}

Primary spinal epidural lymphoma (PSEL) is an entity of lymphomas located in epidural without any other recognizable sites of lymphomas at diagnosis. ${ }^{1}$ An epidural location for lymphoma is observed in $0.1-6.5 \%$ of all the lymphomas; ${ }^{1}$ thus, it is challenging at diagnosis and may easily be misdiagnosed. Here, we presented a case of primary spinal epidural DLBCL with paraplegia as the first manifestation.

\section{Case presentation}

A 39-year-old man was admitted to our hospital on December 23, 2015, with back pain, numbness and weakness of lower limbs for 2 months. Thoracic disc herniation was considered in local hospital 2 months ago; however, conservative treatment did not work. Moreover, the disease quickly progressed to paraplegia on December 24, 2015. The neurologic examination demonstrated a minor motor impairment of lower limbs and reflexes were hyperactive. Anal sphincter tone was without damage, negative Hoffman, Trömner and Babinski's sign. He presented a sensory level of hypoesthesia and loss of thermalgesia at T7. T-SPOT.TB was positive. The enhanced magnetic resonance imaging (MRI) of thoracic vertebra on December 24, 2015 (Figure 1), suggested that thoracic 7 vertebral body, the thoracic 7 and 8 vertebral body accessory tuberculosis was considered, accompanied by intraspinal abscess formation. He was misdiagnosed with thoracic tuberculosis. Posterior pedicle screw fixation + spinal canal decompression + lesion clearance + bone grafting and fusion was performed on December 25, 2015. Surgical pathology suggested DLBCL. The immunohistochemical (Figure 2) hinted tumor cells
Correspondence: Wei Yang Department of Oncology and (ematology, Zhejiang Provincial Integrated Chinese and Western Medicine Hospital (Hangzhou Red Cross Hospital), 208 East Huancheng Road, Hangzhou 310003, Zhejiang, People's Republic of China

Tel +8657I 56109811

Email maxwell1941@I26.com 

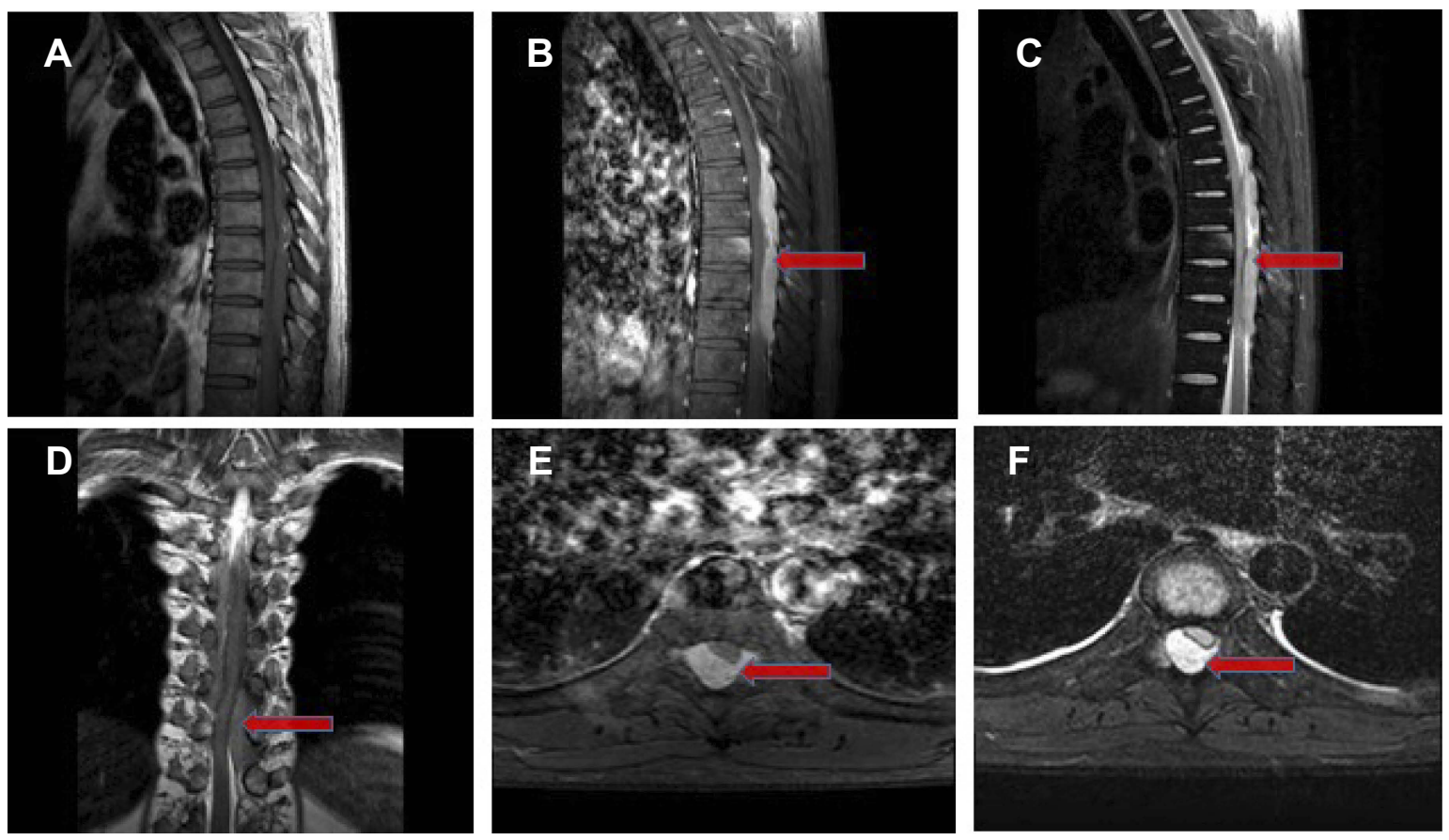

Figure I Epidural soft tissue mass located in the spinal canal outside the back of the dura mater at T4-T9 level, dura mater and spinal cord significantly compressed forward, and the narrowed spinal canal. (A) TIWI at the position of sagittalia, low signal, (B) Sagittal postcontrast TI-weighted image of the thoracic spine reveals enhancing sheetlike lesion in the posterior epidural region compressing the thoracic cord. Shown by red arrow mark, (C) T2WI at the position of sagittalia, high signal, (D) T2WI at coronal section, high signal, (E) TIWI contrast enhancing at transverse section, high signal at T7 level obviously enhanced, (F) T2WI at transverse section, high signal at T7 level. No abnormal changes were observed in the intervertebral disc.

CD20 (+), CD79a (+), PAX-5 (+), Bob-1 (+), Oct2 (+), CD10 $(+), \operatorname{BcL}-2(+), \operatorname{Bcl}-6(+), \operatorname{CD} 15(-), \operatorname{CD} 30(+)$, CD23 (+), CD21 (+), MUM1 $(+)$ and Ki-67 $(+>30 \%)$. Reactive cells CD3 (+), CD5 (+), CD43 (+), CD45RO (+); CDla (-), ALK (-), EMA (-), TdT (-), CD117 (-), HMB45 (-), S100 (-), CD31 $(-)$, CK (-) and EBER (-). 18F-fluorodeoxyglucose (18FFDG)-positron emission tomography/computed tomography (PET/CT) imaging on January 14, 2016 (Figure 3A and B) showed T8-10 vertebral body, retroperitoneal enlarged lymph nodes, left iliac bone and left femur with increased uptake of 18 F-FDG. Based on these, systemic chemotherapy with rituximab + CHOPE (R-CHOPE) was determined as an appropriate treatment for the patient since January 20, 2016. After four cycles of chemotherapy with R-CHOPE, PET/CT on May 12 , 2016 (Figure 3C and D) suggested that, compared with PET/ CT on January 14, 2016, 18F-FDG uptake concentration in the
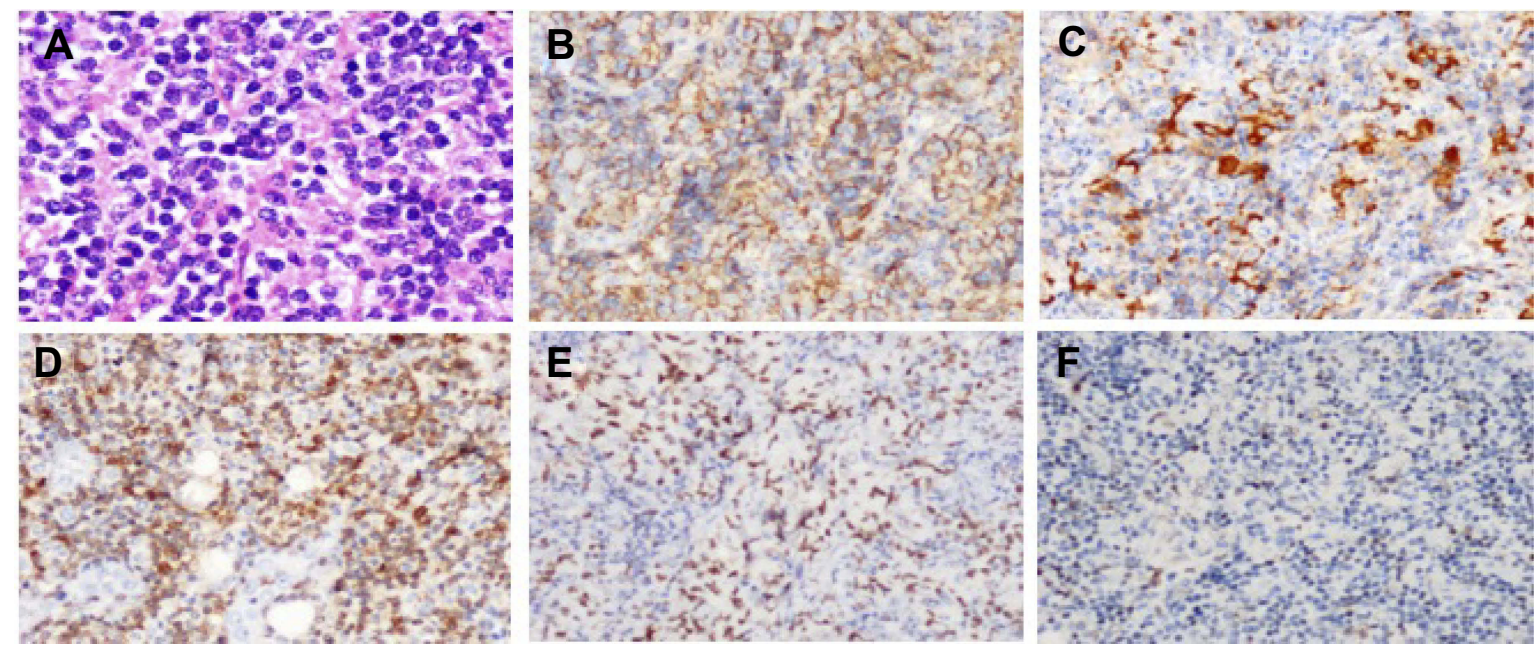

Figure 2 (A) Hematoxylin and eosin stain (×40), (B) CD20 (+) (×20), (C) CDI0 (+) (×20), (D) BCL-2 (+) (×20), (E) BCL-6 (+) $(\times 20),($ F) C-MYC $(+)(\times 20)$. 

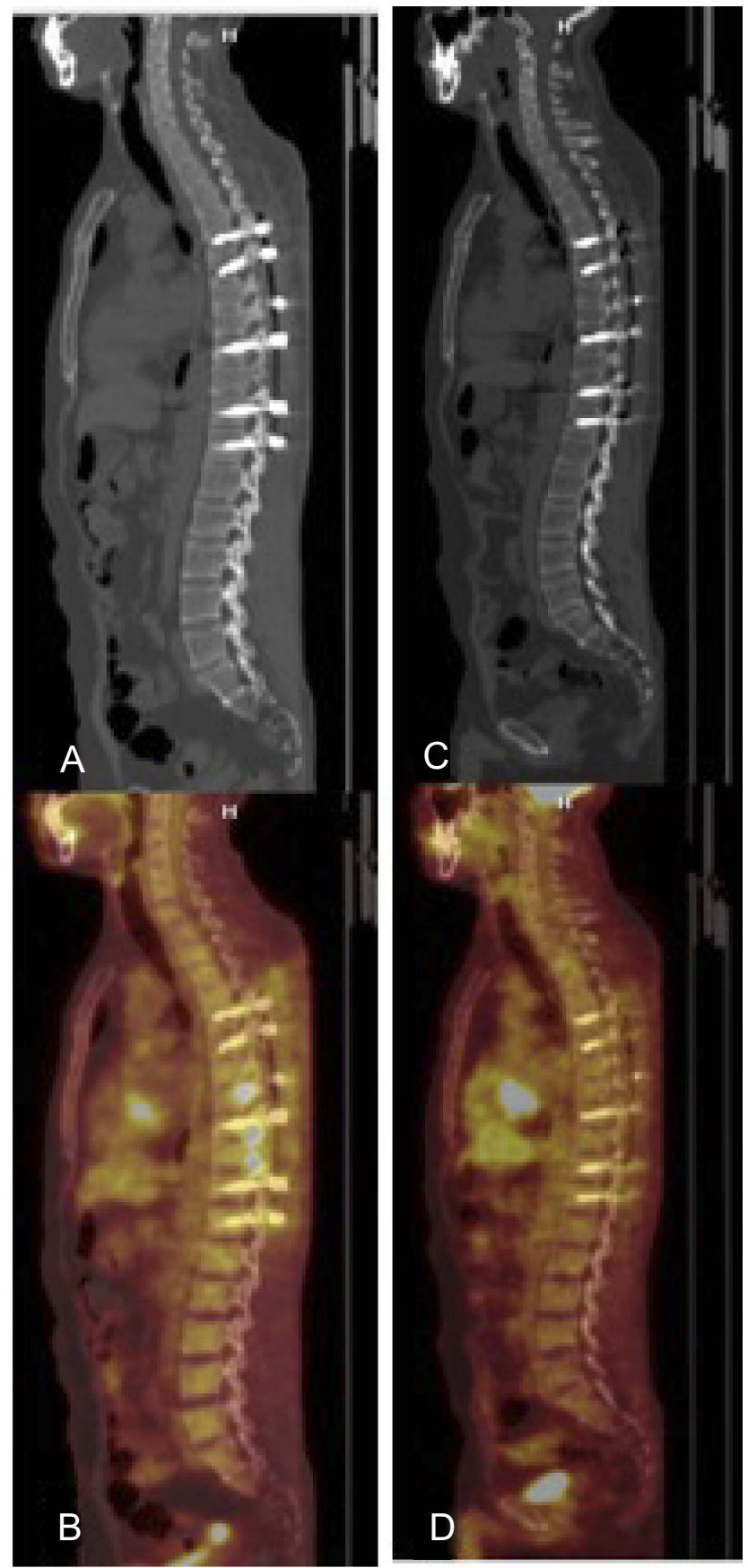

Figure 3 (A and B) PET/CT on January 14, 2016, showed T8-10 vertebral body, retroperitoneal enlarged lymph nodes, left iliac bone and left femur with increased uptake of 18F-FDG. (C and D) PET/CT on May 12, 2016, showed that 18F-FDG uptake concentration in the original area all disappeared.

original area all disappeared, suggesting that the tumor was relieved. Then, the strength of both lower extremities gradually recovered, and he could walk. After another two cycles of chemotherapy with R-ECHOP on May 14, 2016, and on June 11, 2016, respectively, the patient went to follow-up time. During the nearly 2-year follow-up, the disease still has no relapse.
Ethical approval was not necessary for the case report. The patient has consented for the publication of the present case report.

\section{Discussion}

In this case, the patient was misdiagnosed as thoracic disc herniation and thoracic tuberculosis successively (Figure 4). In the previous reported study, ${ }^{2}$ the overall specificity and sensitivity of the T-SPOT.TB were $92.83 \%$ and $83.67 \%$, respectively. Patients with cured tuberculosis tended to induce false-positive results. In this case, T-SPOT.TB was false-positive.

PSEL usually occurs in 40-50 years old, and the malefemale ratio is 1.6:1. The 3-year overall survival was $81.1 \%$, and disease-free survival rate was $46.3 \%{ }^{3}$ The origin of PSEL is thought to be derived from lymphatic tissue along the venous plexus in the epidural space or the paravertebral lymphoid rests or the vertebral body, which later extends to the epidural space. ${ }^{4}$ The most common presenting symptoms reported included lower limb weakness, localized back pain, and bladder dysfunction. The symptoms and signs of the disease depend on the location and size of the tumor. The onset is usually subacute, ranging from days to weeks. The clinical symptoms are divided into two stages: the first stage is the prodromal stage, which is characterized by localized back pain and incidental radicular pain, which lasts from several months to 1 year; the second stage is the progressive stage, which is characterized by rapid neurological decline due to nerve compression and lasts for 2 to 8 weeks. There were some published case reports about primary spinal epidural DLBCL (Table 1). ${ }^{5-7}$

For patients with high suspicion of PSEL, MRI is helpful for diagnosis. MRI plain scan usually showed T1W1 signal or low signal, T2WI signal or high signal, but some literature reported that T2WI showed low signal, may be related to the relative density of tumor cells. Hyperintense T2 signal greater than that of adjacent fat with adjacent expansile bone disease differentiates epidural metastases from lymphoma. ${ }^{8}$

Primary spinal epidural non-Hodgkin's lymphoma (NHL) accounts for less than $1 \%$ of all NHL. ${ }^{5}$ Most epidural lymphomas are moderately and well-differentiated B-cell lymphoma. DLBCL is the most common type, accounting for $1.8 \%$ of all DLBCL. Pathological examination revealed atypical lymphocyte proliferation, and immunohistochemistry showed positive cluster of differentiation (CD)20, negative leukocyte common antigen and $\mathrm{CD} 138, \mathrm{CD} 30$ and $\mathrm{CD} 3$. 


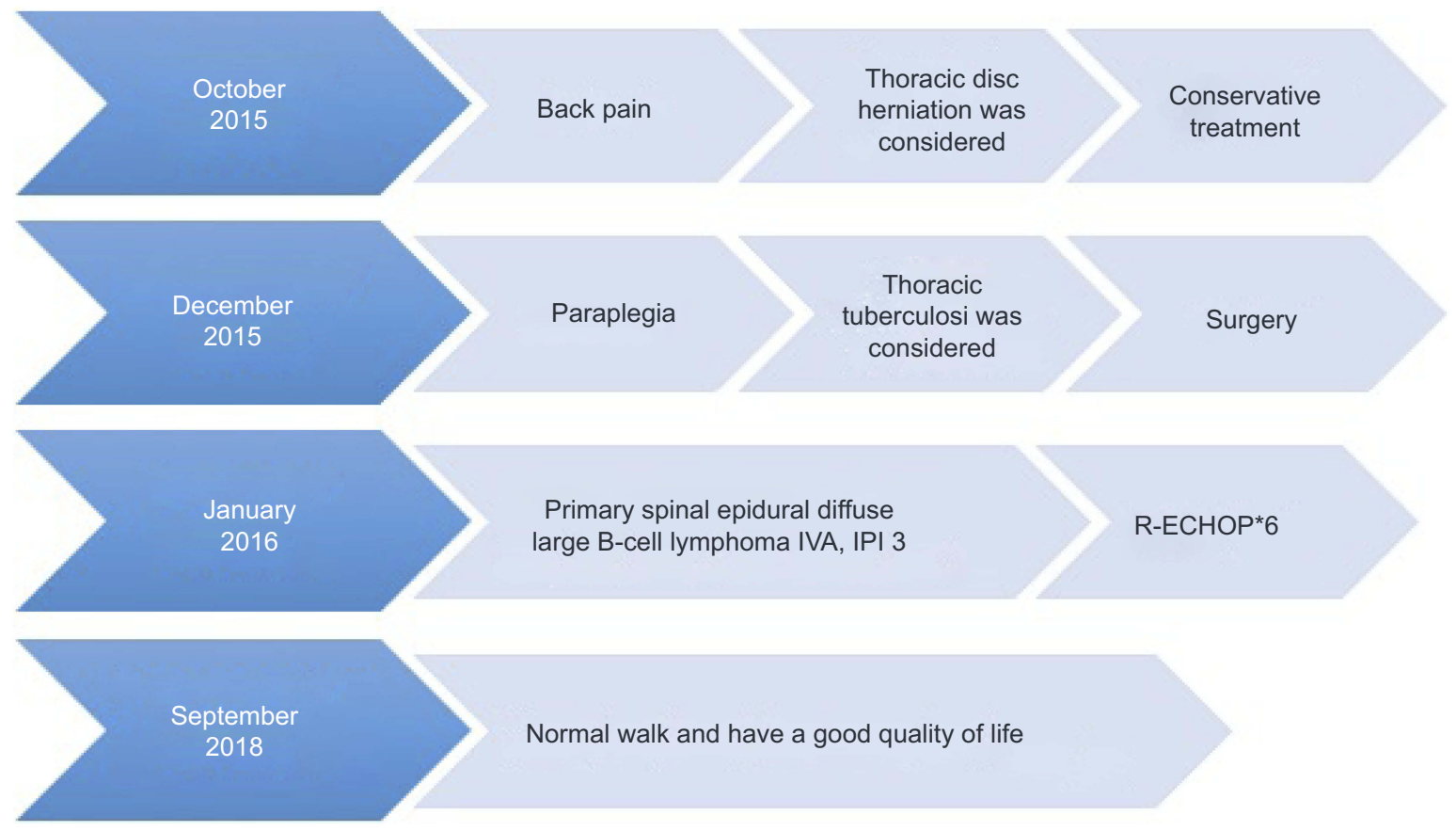

Figure 4 The process of therapy.

Table I Published case reports about primary spinal epidural diffuse large B-cell lymphoma

\begin{tabular}{|l|l|l|l|l|}
\hline First author and year & Patient & Location & The first manifestation & Pathology \\
\hline $\begin{array}{l}\text { Liu SZ et al, 2018 } \\
\text { Córdoba-Mosqueda et al, 2017 }\end{array}$ & $\begin{array}{l}\text { A 43-year-old male } \\
\text { A 45-year old male }\end{array}$ & T5 & $\begin{array}{l}\text { Complete paralysis } \\
\text { Tn anterior spinal syndrome with hypoesthesia and loss } \\
\text { of thermalgesia } \\
\text { Pain at the level of left infra mammary region }\end{array}$ & DLBCL \\
Jagtap SA et al, 2013 & A 32-year-old female & T3-T4 & DLBCL \\
\hline
\end{tabular}

The specific management has not been established yet. Surgery is the mainstay of treatment for cord decompression with aggressive chemotherapy in conjunction with radiotherapy is associated with good functional outcome. ${ }^{9}$ It is not known whether preventive intrathecal injection is necessary. In this case, the patient refused to take preventive intrathecal injection.

All in all, PSEL should be suspected in patients with spinal cord compression with imaging showing isointense, homogeneous extradural contiguous level compressive soft-tissue lesion without bony involvement and previous history of cancer.

\section{Ethics approval and consent to participate}

The patient consent for publication of the case report was written informed consent and all identifying information was removed. No other ethical parameters beyond privacy were affected as this was not a clinical trial.

\section{Abbreviations}

DLBCL, diffuse large B-cell lymphoma; PSEL, primary spinal epidural lymphoma; 18F-FDG, 18F-fluorodeoxyglucose; PET/CT, positron emission tomography/computed tomography; R-CHOPE, rituximab + CHOPE; NHL, nonHodgkin's lymphoma; MRI, magnetic resonance imaging.

\section{Disclosure}

The authors report no conflicts of interest in this work.

\section{References}

1. Cugati G, Singh M, Pande A, et al. Primary spinal epidural lymphomas. J Craniovertebr Junction Spine. 2011;2:3-11. doi:10.4103/09748237.85307 
2. Di L, Li Y. The risk factor of false-negative and false-positive for TSPOT.TB in active tuberculosis. J Clin Lab Anal. 2018;32:e22273. doi:10.1002/jcla.2018.32.issue-2

3. Xiong L, Liao LM, Ding JW, Zhang ZL, Liu AW, Huang L. Clinicopathologic characteristics and prognostic factors for primary spinal epidural lymphoma: report on 36 Chinese patients and review of the literature. BMC Cancer. 2017;17:131. doi:10.1186/s12885017-3093-z

4. Mora J, Wollner N. Primary epidural non-Hodgkin lymphoma: spinal cord compression syndrome as the initial form of presentation in childhood non-Hodgkin lymphoma. Med Pediatr Oncol. 1999;32:102-105.

5. Liu SZ, Zhou X, Song A, Huo Z, Wang YP, Liu Y. Primary spinal epidural non-Hodgkin's lymphoma causing complete paralysis. $Q J M$. 2018. doi:10.1093/qjmed/hcy151
6. Cordoba-Mosqueda ME, Guerra-Mora JR, Sanchez-Silva MC, Vicuna-Gonzalez RM, Torre AI. Primary spinal epidural lymphoma as a cause of spontaneous spinal anterior syndrome: a case report and literature review. J Neurol Surg Rep. 2017;78:e1-e4.

7. Jagtap SA, Patil AS, Kesavdas C, Radhakrishnan N, Soni H, Satish KS. Primary spinal epidural diffuse large B-cell lymphoma. Neurol India. 2013;61:532-534. doi:10.4103/0028-3886.121940

8. Haque S, Law M, Abrey LE, Young RJ. Imaging of lymphoma of the central nervous system, spine, and orbit. Radiol Clin North Am. 2008;46:339-361. ix. doi:10.1016/j.rcl.2008.04.003

9. Monnard V, Sun A, Epelbaum R, et al. Primary spinal epidural lymphoma: patients' profile, outcome, and prognostic factors: a multicenter rare cancer network study. Int J Radiat Oncol Biol Phys. 2006;65:817-823. doi:10.1016/j.ijrobp.2006.01.002

\section{Publish your work in this journal}

OncoTargets and Therapy is an international, peer-reviewed, open access journal focusing on the pathological basis of all cancers, potential targets for therapy and treatment protocols employed to improve the management of cancer patients. The journal also focuses on the impact of management programs and new therapeutic

Submit your manuscript here: https://www.dovepress.com/oncotargets-and-therapy-journal agents and protocols on patient perspectives such as quality of life, adherence and satisfaction. The manuscript management system is completely online and includes a very quick and fair peer-review system, which is all easy to use. Visit http://www.dovepress.com/ testimonials.php to read real quotes from published authors. 